\title{
ESPACIOS PROTEGIDOS: EL CASO DE INGLATERRA Y GALES
}

\author{
POR \\ MICHAEL BARKE
}

\section{Introducción}

Este artículo tiene como objetivo examinar la protección de las áreas rurales de Inglaterra y Gales y está dividido en tres secciones. En primer lugar, se investigará el desarrollo de la política y la legislación en relación con la protección del medio ambiente de las áreas rurales de Inglaterra y Gales. En segundo lugar, se estudiarán los rasgos principales del sistema actual para administrar el cambio de los paisajes y para proteger dichos paisajes. Finalmente se analizará, con más profundidad, el carácter de algunos de los problemas actuales en relación con la protección ambiental, junto con la consideración de algunos intentos de solución de estos problemas. Aunque se examinará toda la gama de medidas aplicadas para proteger estas áreas, se prestará mayor atención a lo que probablemente es el aspecto más conocido, importante y controvertido de tal protección, es decir, los diez Parques Nacionales de Inglaterra y Gales.

\section{Espacios protegidos: el desarrollo de la legislación}

Durante el siglo XIx y con anterioridad al mismo, la protección de los paisajes en Inglaterra y Gales fue considerada «asunto privado»

Michael Barke, División de Geografía y Medio Ambiente, Universidad de Northumbria. Newcastle upon Tyne. Versión española revisada por Elvira Urzainqui, Inst. Economía y Geografía, CSIC.

Estudios Geográficos
Tomo LVII, n. ${ }^{\circ} 227$, abril-junio 1997 
del propietario. Sin embargo, a principios del siglo xx, la presión sobre el campo aumentó hasta tal punto, que poco a poco se fue aceptando el principio de una legislación estatal para proteger las áreas de belleza natural.

Inicialmente tales presiones estaban relacionadas con la desaparición de espacios de gran valor paisajístico por el desarrollo esporádico y sin planificar de la construcción; por consiguiente, estos espacios solían estar situados más en las periferias de áreas metropolitanas que en áreas rurales alejadas. El establecimiento en 1926 de un importante "grupo de presion - The Council for the Preservation of Rural England (El Consejo para la Conservación de la Inglaterra Rural)-, fue, en gran medida, una respuesta a las preocupaciones por el incontrolado proceso de suburbanización, más que a las amenazas al futuro de las áreas rurales alejadas (Cherry, 1975).

Sin embargo, los nuevos avances de los años 20 y 30 lograron que las zonas más periféricas y montañosas de Inglaterra y Gales llegaran a estar incluidas entre las preocupaciones por la protección de las áreas rurales. En particular, el concepto de reservar áreas rurales -especialmente las de gran atractivo paisajístico para ocio y recreofue cobrando cada vez más importancia. Esto se debió principalmente a la aparición de nuevas demandas en las áreas rurales por parte de los residentes urbanos. La mayor movilidad de estos últimos debido al aumento de vehículos contribuyó a parte de tales demandas; pero mucho más importante fue la creciente popularidad de las «actividades al aire libre», sobre todo la práctica de excursiones a pie, del camping y del ciclismo. A esto se sumaba la creciente proporción de la población británica que, aunque urbana, deseaba pasar su tiempo libre en zonas rurales. De acuerdo con tales demandas, se formaron nuevas organizaciones para facilitar y, por lo menos parcialmente, proporcionar tales actividades.

Por ejemplo, la National Trust (Entidad Nacional Protectora del Patrimonio Histórico y Natural) se había creado en 1895, pero fue en el siglo xx cuando se convirtió en un organismo de carácter jurídico desarrollándose como la entidad no gubernamental de conservación más importante (Feeden, 1974). Dicha entidad llegó a ser realmente decisiva para la adquisición y apertura al público de tierras y propiedades especialmente fincas que hasta entonces habían sido privadas. 
En 1923 dicha entidad poseía 102 de tales propiedades (Curtis, 1991), cifra que posteriormente se ha duplicado (Open Information, 1985). En 1930 se fundó la Youth Hostel Association (Asociación de Albergues Juveniles) para facilitar alojamiento básico y barato a los excursionistas y ciclistas en áreas rurales. Además, el interés por la salud física entre los habitantes urbanos, que se venía expresando desde mediados del siglo XIX, aumentó la importancia de las demandas de un mayor acceso a los espacios libres para recreo y ocio, además de un mayor uso de los mismos.

En 1929 se creó un Comité de Investigación encargado de examinar las posibilidades de desarrollar un sistema de Parques Nacionales similar al existente en los Estados Unidos. El gobierno no intervino de forma inmediata, pero la situación llegó al límite a mediados de los años 30, cuando los propietarios de los grouse moors en el norte de Inglaterra (usados sólo para la caza) negaron el acceso a los excursionistas procedentes de ciudades tales como Manchester, Liverpool, Sheffield, Leeds, Bradford, Derby y Nottingham. En protesta, se llevó a cabo una campaña de "entrada ilegal masiva» en la que los ciudadanos reivindicaban, por lo menos, un acceso limitado, a efectos de recreo, a estos espacios abiertos de propiedad privada e infrautilizados (Shoard, 1987).

Por lo tanto, ya antes de la Segunda Guerra Mundial, varios factores estaban originando una situación en la cual era casi inevitable la intervención gubernamental para la protección de las áreas rurales. La elección de un gobierno laborista reformista en 1945 propició dicha intervención. Aunque su interés no era sólo el campo, la Town and Country Planning Act (La Ley de Planificación Urbana y Rural) de 1947 fue y sigue siendo (con posteriores enmiendas) el principal instrumento para el control del desarrollo. Los principales organismos municipales se convirtieron en autoridades de planificación, encargados de redactar planes de desarrollo para sus áreas y de gestionar el control de la urbanización. De hecho, esto significa que cualquier nueva edificación o ampliación sólo se puede efectuar después de que las autoridades de planificación hayan concedido el permiso de construcción. Este sistema opera en todo el país y, potencialmente al menos, facilita una eficaz medida de control de todas las formas de desarrollo. Sin embargo, lo que nos interesa particularmente son las áreas rurales que tienen niveles adicionales de protección.

$$
-149-
$$


La primera medida especifica relativa a los niveles adicionales de protección para áreas de alto nivel paisajístico y ambiental fue la $\mathrm{Na}$ tional Parks and Access to the Countryside Act (Ley de Parques Nacionales y Acceso al Campo) de 1949. Dicha Ley «sentaba las bases para proteger espacios de gran valor paisajístico y para desarrollar el campo con fines recreativos (Cherry, 1975: 2). La ley establecía una National Parks Commission (Comisión de Parques Nacionales) (la actual Countryside Commission -Comisión del Campo-) encargada de crear diez Parques Nacionales (Lake District, Northumberland, Peak District, Yorkshire Dales, North York Moors, Dartmoor y Exmoor en Inglaterra y en Gales, Snowdonia, Brecon Beacons y Pembrokeshire (cuadro I y figura 1). Dos espacios más -Norfolk Broads y South Downs- no fueron aceptados como Parques Nacionales, aunque el primero ya goza de un estatus de protección similar (Countryside Commission, 1977).

A la National Parks Commission le correspondía:

1. Designar los Parques Nacionales. 2. Designar las Areas of Outstanding Natural Beauty - AONBs (Areas de Gran Belleza Natural). 3. Conservar y mejorar la belleza natural del campo, especial-

CuAdro I

PARQUES NACIONALES

\begin{tabular}{lrlcr}
\hline Nombre & $\begin{array}{c}\text { Superficie } \\
(\mathbf{k m 2})\end{array}$ & \multicolumn{1}{c}{$\begin{array}{c}\text { Fecha de } \\
\text { declaración }\end{array}$} & $\begin{array}{c}\text { Residentes } \\
(\mathbf{m i l e s})\end{array}$ & $\begin{array}{c}\text { Visitantes/Año } \\
\text { (millones) }\end{array}$ \\
\hline Brecon Beacons ..... & 1350 & Abril 1957 & 32.2 & 7 \\
Dartmoor ............ & 945 & Octubre 1951 & 29.1 & 8 \\
Exmoor .............. & 686 & Octubre 1954 & 10.0 & 3 \\
Lake District ........ & 2280 & Mayo 1951 & 40.0 & 20 \\
Northumberiand .... & 1031 & Abril 1956 & 2.2 & 1 \\
North York Moors ... & 438 & Noviembre 1952 & 27.0 & 11 \\
Peak District ........ & 1404 & Abril 1951 & 37.4 & 20 \\
Pembrokeshire & & & & \\
Coast ................ & 583 & Febrero 1952 & 23.0 & 13 \\
Snowdonia ........... & 2170 & Octubre 1951 & 23.8 & 8 \\
Yorshire Dales ....... & 1760 & Octubre 1954 & 18.6 & 9 \\
\hline
\end{tabular}

Fuente: D. and J. Poore (1987). 


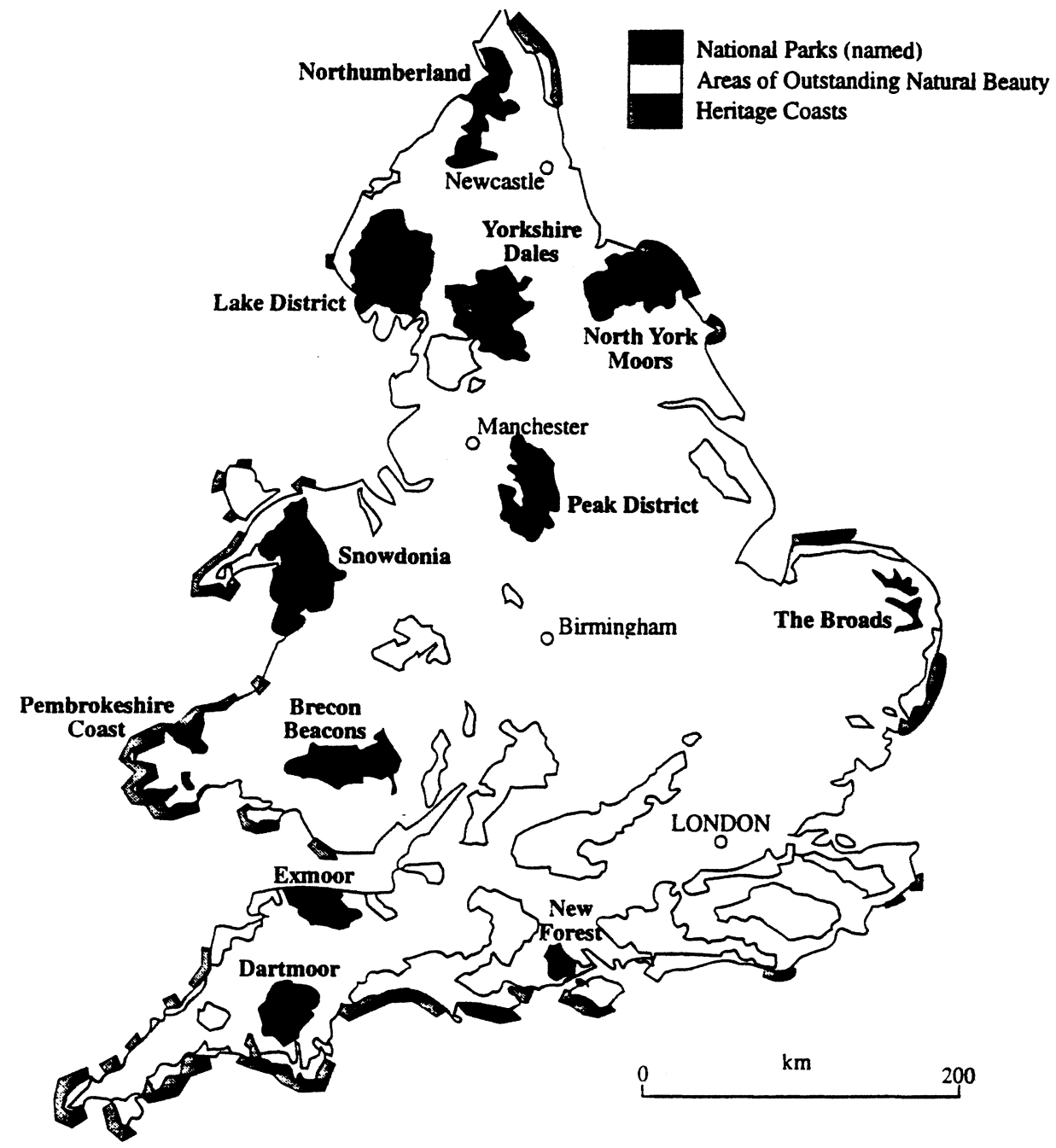

Figura 1.-Parques Nacionales, Areas de gran belleza natural y patrimonios costeros en Inglaterra y Gales 
mente en relación con los Parques Nacionales y AONBs. 4. Asesorar y asistir a las autoridades locales. 5. Fomentar la provisión de instalaciones para el aprovechamiento de los Parques Nacionales. (Open Información, 1985).

Es evidente que las funciones descritas en los puntos (3) y (5), en algunas circunstancias, podrían entrar en conflicto. Otras dos características de la National Parks and Access to the Countryside Act de 1949, también sugieren un conflicto potencial en el seno de esta norma concreta.

La Ley establecía el Natural Conservancy Council (Consejo para la Conservación de la Naturaleza) integrado por 19 miembros nombrados por el Ministro de Medio Ambiente. A este organismo y a las autoridades locales se les encargó designar reservas naturales en zonas de especial significado ecológico o geológico, y en espacios más pequeños de «especial interés» ecológico. Posteriormente, estos fueron conocidos como Sites of Special Scientific lnterest-SSSIs (Sitios de Especial Interés Científico). En esta sección concreta de la Ley se pretendía abiertamente promover la conservación y protección de los espacios naturales pero no el acceso del público (Newby, 1979). Sin embargo, otra sección de la Ley requería que los County Councils (Diputaciones Provinciales) hiciesen un estudio de sus espacios para encontrar «derechos de paso» públicos y facilitar caminos para excursionistas, ciclistas y jinetes: en otras palabras, para facilitar al público en general un mayor acceso al campo. No cabe duda de que este conflicto entre la conservación por una parte, y los usos recreativos por otra, sigue siendo el problema fundamental de la protección ambiental en las áreas rurales británicas (McEwan and McEwan, 1982).

Aunque la Ley de 1949 era impresionante por su alcance, se avanzaba muy lentamente. Por ejemplo, fueron necesarios ocho años para establecer los diez Parques Nacionales, y aún más tiempo para designar las Areas of Outstanding Natural Beauty. El primer Parque, en la Península de Gower en Gales, no se declaró hasta 1956; y los restantes se fueron declarando durante los años 80 (Poore and Poore, 1987). Asimismo, el proceso de establecer sendas de largo recorrido resultó extraordinariamente lento y la primera, Pennine Way, no se terminó hasta 1965 (Owens, 1990). Los diversos organismos 
creados por la Ley carecían de los recursos humanos y materiales necesarios para cumplir sus compromisos. Fueron necesarias laboriosas negociaciones entre estas nuevas autoridades, las locales ya existentes y los propietarios. Parte de la legislación posterior a la Ley de 1949 ha modificado las disposiciones para la protección del paisaje natural británico. Las principales iniciativas han sido la Countryside Act (Ley del Campo) de 1968, la Nature Conservancy Act (Ley del Consejo para la Conservación de la Naturaleza) de 1973, y la Wildlife and Countryside Act (Ley de la Fauna y del Campo) de 1981.

En los años posteriores a 1949, la presión sobre el campo británico creció enormemente. El rápido aumento de los propietarios de vehículo incrementó considerablemente la movilidad de los ciudadanos; además, la disponibilidad de más tiempo de ocio y de mayores niveles de poder adquisitivo, impulsaron la extensión del uso del campo con fines recreativos (Dower, 1965). Otras presiones procedían de la expansión física de las áreas urbanas y la consiguiente preocupación por la pérdida de tierras cultivables (Best and Champion, 1970). Este fue el trasfondo de la aprobación de la Countryside Act (Ley del Campo) de 1968. La característica más destacada de esta Ley fue la creación de la Countryside Commission (Comisión del Campo) para reemplazar a la Natural Parks Commission (Comisión de Parques Nacionales); se estimaba que todas las áreas rurales -no sólo los diez Parques- necesitaban la atención especial que pudiera prestar la Comisión. Se otorgó un papel más amplio a la Countryside Commission, aunque contenía el mismo conflicto potencial entre conservación y uso recreativo. La Comisión era responsable de la conservación del campo al mismo tiempo que debía capacitar al público para disfrutar del mismo. Esto incluía medidas para fomentar la provisión de instalaciones de recreo.

Hubo una nueva iniciativa relativa a las competencias concedidas a las autoridades locales y a los propietarios para crear los llamados Country Parks (Parques del Campo) y sitios para merendar al aire libre, que estarían situados en el entorno rural en lugares de fácil acceso para los visitantes. En realidad, estos Parques iban a funcionar como «filtros» para orientar al público hacia el uso recreativo del área rural y, al mismo tiempo, evitar la presión sobre espacios más alejados y ambientalmente más vulnerables de la Gran Bretaña rural (Newby, 1988). Para facilitar el acceso al campo, se 
solicitó la colocación de postes indicadores en todas las sendas públicas.

Antes de su desaparición, la National Parks Commission había empezado a interesarse por la conservación y explotación de las costas. La Countryside Commission se encargó de continuar este trabajo y propuso que ciertas extensiones del litoral no desarrolladas fueran declaradas Heritage Coasts (Costas Protegidas) y provistas de medidas protectoras especiales. El gobierno aceptó estas recomendaciones, y apremió a las autoridades locales a definir tales áreas costeras y preparar proyectos de gestión para las mismas conjuntamente con la Countryside Commission. Grandes sectores de estas costas protegidas coinciden con las fronteras costeras de los Parques Nacionales y las AONBs, mientras la National Trust había adquirido también importantes zonas de estas costas para asegurar su conservación.

Durante los años 60 se había extendido la idea de que la conservación del paisaje rural y la protección de la flora y fauna, aunque estrechamente vinculadas, no eran lo mismo. La Nature Conservancy creada en 1949 se había ocupado de la designación de las reservas naturales. En 1973, este organismo se convirtió en el Nature Conservancy Council (ahora llamado English Nature), y se le asignaron las siguientes funciones principales:

1) Asesorar al Gobierno en la política de conservación de la naturaleza y proporcionar consejos e información sobre la misma. 2) Establecer y administrar las reservas naturales. 3) Promover la investigación en el ámbito de la conservación.

En el proceso de creación de reservas naturales potenciales, un paso inicial fue su identificación como áreas de interés especial. Se consideró necesaria una protección provisional para tales áreas y se inició el proceso de designación de Sites of Special Scientific Interest -SSSIs- (Sitios de Especial Interés Científico). La Wildlife and Countryside Act de 1981 otorgaba más competencias al Nature Conservancy Council en relación con los SSSls.

Hasta los años 70, en general se daba por sentado que las primeras políticas para la conservación y protección del campo y de la fauna eran compatibles con los métodos de cultivo existentes. Sin em-

$$
-154-
$$


bargo, los cambios de estructura y, especialmente, la gran intensificación de la agricultura durante los años 60 y 70 planteaban nuevos problemas (Green, 1981). Estos incluían cambios significativos en el paisaje, reducción de los hábitats de flora y fauna, así como problemas de acceso.

Estas inquietudes dieron lugar a la Wildlife and Countryside Act de 1981. Las competencias potenciales para la protección ambiental incorporadas en esta Ley son considerables. Sin embargo, el objetivo de una conservación efectiva sigue siendo problemático, principalmente por la limitación de los recursos disponibles para ejecutar dichas competencias. La Ley permite que el Nature Conservancy Council compre SSSI o indemnice a los propietarios cuando la creación de un SSSI haya reducido el valor de la tierra. En realidad, no se disponía de recursos complementarios para cubrir tal gasto adicional (Cox and Love, 1983). En la práctica, por lo tanto, el Nature Conservancy Council ha tenido que lograr acuerdos voluntarios y la cooperación de los propietarios. La Ley de 1981 también otorgaba competencias al Consejo para declarar tierras de importancia nacional como National Nature Reserves (Reservas Naturales Nacionales) y para administrarlas. El Consejo tiene también autoridad para conceder ayudas económicas para gastos relacionados con la conservación de la naturaleza. Finalmente, se aprobaron nuevas competencias para restringir ciertas actividades agrícolas, en los moors and heath lands (páramos y brezales) situados dentro de los Parques Nacionales, especialmente el arado de los mismos.

La política de protección de áreas ambientalmente vulnerables ha estado también influida por las reglamentaciones europeas. Estas se han aplicado principalmente al ámbito de la política agraria siendo la más importante, en este contexto, la relativa a la disponibilidad de fondos para apoyar la agricultura favorable a la conservación de los paisajes y hábitats (Blunden and Curry, 1988). Esto es particularmente importante en espacios de gran valor ecológico sometidos a fuerte presión económica para la intensificación agrícola. Desde mediados de los 80 se han venido designando áreas específicas susceptibles de tal apoyo económico. 


\section{El sistema actual de protección del paisaje}

De acúerdo con lo dicho anteriormente, es evidente que la responsabilidad de la protección del paisaje natural en Inglaterra y Gales depende de una serie de mecanismos que han ido evolucionando a partir de la Segunda Guerra Mundial. Esta sección, por lo tanto, se dedicará a describir el sistema actual y perfilar las principales características de las diversas categorías de áreas protegidas.

La Countryside Commission es la principal entidad nacional involucrada en la protección del espacio natural, cuyas responsabilidades principales son:

1 Conservar la belleza paisajística del campo. 2) Desarrollar y mejorar las instalaciones de recreo y de acceso al campo. 3) Asesorar al gobierno en los asuntos relativos al campo.

La Comisión es un organismo independiente, aunque financiado por el gobierno central, cuyas funciones incluyen desde asesorar, apoyar la investigación y distribuir fondos para la mejora del paisaje (por ejemplo, plantar árboles) hasta la provisión de instalaciones apropiadas para el uso recreativo. Su principal cometido, sin embargo, se centra en el aspecto físico del campo y, en términos generales, si se produce un conflicto entre intereses recreativos e intereses paisajísticos, se da prioridad a estos últimos (Seabrooke and Miles, 1993). La Countryside Commission por derecho propio no es propietaria de ninguna tierra, pero diseña y asesora las políticas relativas a los Parques Nacionales y las AONBs. En respuesta a la creciente demanda recreativa rural, la tendencia general de la Comisión ha sido crear un doble nivel de estructuras para su satisfacción. Ha promovido el desarrollo de las llamadas honeypots (zonas de especial atracción) hacia donde se canaliza un gran número de visitantes urbanos con coche mediante la concentración de instalaciones de recreo y aparcamiento. De esta forma se liberan amplios espacios más remotos para el uso de aquella minoría que representan los wilderness seekers (buscadores de soledad) (Newby, 1988).

Aunque la Countryside Commission es la organización con máxima responsabilidad sobre los Parques Nacionales, cada uno de los diez Parques es administrado por una autoridad propia. En el Peak Dis-

$$
-156-
$$


trict y el Lake District se han constituido autoridades especiales de planificación, mientras que en los restantes Parques, la autoridad reside en una comisión de la Country Council (Diputación Provincial) pertinente, y si el Parque cruza la frontera entre dos condados es administrado por una comisión conjunta. Una tercera parte de los miembros componentes de la autoridad son nombrados por el gobierno y los restantes pertenecen a grupos de intereses de la zona. La función principal de la comisión es desarrollar y ejecutar un plan que perfile las estrategias a seguir dentro del Parque para lograr sus objetivos. De hecho, éste es un plan estructural que propone las políticas para el uso y la conservación de los recursos, la zonificación según intensidades de uso y el control de la circulación. En la preparación de dicho plan es imprescindible que haya coordinación entre agencias y los individuos adecuados; éstos son, por supuesto, la Countryside Commission, los propietarios locales y otros organismos.

Los Parques Nacionales cubren aproximadamente un 9\% de la superficie total de Inglaterra y Gales y dentro de sus límites viven casi 250.000 personas. Así, aunque los Parques contienen muchas superficies de paisajes «vírgenes» que siguen en su estado natural, no son realmente espacios desiertos ni ciertamente están deshabitados. Aquí radica una de las características singulares y la fuente de muchos de los problemas administrativos de los Parques Nacionales de Inglaterra y Gales. Otro aspecto importante es que, a pesar de su nombre, los Parques Nacionales no son propiedad del estado; se les considera propiedad «nacional» en el sentido de que su atractivo y las oportunidades que proporcionan para el ocio, hacen de ellos un valor especial para toda la nación. Sin embargo, el carácter de la «propiedad» de la tierra y especialmente el considerable número de propietarios añaden una complicación importante a la administración de los Parques. La declaración oficial de Parques Nacionales no excluye la posibilidad de otras formas de protección ambiental e, inevitablemente, los Parques Nacionales contienen dentro de sus límites muchas de las otras categorías de área protegida, por ejemplo, National Nature Reserves, SSSIs, antiguos monumentos declarados de interés histórico tales como Hadrian's Wall (la Muralla de Adriano), construcciones protegidas (normalmente edificios antiguos de especial mérito arquitectónico que no pueden ser alterados). El cuadro II resume estas características para cada uno de los diez Parques Nacionales. 
Cuadro II

AREAS PROTEGIDAS DENTRO DE LOS PARQUES NACIONALES

\begin{tabular}{|c|c|c|c|c|c|}
\hline Nombre & $\begin{array}{l}\text { Reservas } \\
\text { naturales } \\
\text { nacionales } \\
\text { núm. (ha) }\end{array}$ & $\begin{array}{l}\text { Reservas } \\
\text { naturales } \\
\text { locales } \\
\text { núm. (ha) }\end{array}$ & $\begin{array}{l}\text { Sitios de } \\
\text { especial } \\
\text { interés } \\
\text { científico } \\
\text { núm. (ha) }\end{array}$ & $\begin{array}{l}\text { Edificios } \\
\text { protegidos } \\
\text { núm. }\end{array}$ & $\begin{array}{l}\text { Monumentos } \\
\text { nacionales }\end{array}$ \\
\hline Brecon Beacons . & $4(783)$ & $3(218)$ & $44(27.135)$ & 1073 & 142 \\
\hline Dartmoor ......... & $3(250)$ & $4(59)$ & $28(15.364)$ & 1950 & 436 \\
\hline Exmoor ............. & - & 2 & 6 & 710 & 151 \\
\hline Lake District ..... & 4 & 13 & $79(32,80)$ & 1422 & 135 \\
\hline $\begin{array}{l}\text { Northumberland . } \\
\text { North York }\end{array}$ & 2 & 2 & $20(9.000)$ & 200 & 651 \\
\hline Moors ............... & 3 & $1(1.000)$ & 40 & 830 & 300 \\
\hline $\begin{array}{l}\text { Peak District ..... } \\
\text { Pembrokeshire }\end{array}$ & $1(262)$ & $?$ & 55 & 2364 & 199 \\
\hline Coast .............. & 3 & 21 & $48(7700)$ & 650 & 185 \\
\hline Snowdonia ........ & $16(6731.9)$ & $1(36)$ & $\begin{array}{l}71 \\
(32.490 .5)\end{array}$ & 730 & 137 \\
\hline Yorkshire Dales . & 2 & 6 & 56 & 804 & 114 \\
\hline
\end{tabular}

Fuente: Countryside Commission (1993).

Las $A O N B s$ representan la segunda responsabilidad importante de la Countryside Commission y forman el segundo nivel de áreas protegidas en Inglaterra y Gales. Sin embargo, en general, la promoción del recreo y turismo no constituye un motivo tan fuerte como en el caso de los Parques Nacionales. Las $A O N B s$ son áreas de gran calidad paisajística, pero carecen de las extensas superficies de campo abierto que caracterizan a todos los Parques Nacionales. Mientras que la mayoría de estos últimos están situados en el norte de Gran Bretaña, las AONBs están ubicadas en el sur (Figura 1). De éstas, 38 cubren unos 19.287 kilómetros cuadrados equivalentes al $12,8 \%$ de la superficie de Inglaterra y Gales. El principal objetivo es la conservación de la belleza natural, que corresponde a las autoridades locales respectivas. La declaración de una $A O N B$ dificulta el desarrollo intensivo a gran escala y favorece que las autoridades locales o la Countryside Commission proporcionen fondos para medidas de conservación. En estas áreas, los controles sobre la construcción son especialmente estrictos (Curtis, 1991). 
Durante los años 70 y 80 se procedió a la declaración de Heritage Coasts (Patrimonios Costeros). Unas 39 superficies litorales distintas ya cuentan con dicha calificación (Figura 1) y cubre un $31 \%$ del litoral total de Inglaterra y Gales, es decir, unos $1.370 \mathrm{Kms}$. Normalmente el área protegida se extiende hacia el interior en una distancia de unos $2 \mathrm{Kms}$. La National Trust organizó con éxito un llamamiento especial (Enterprise Neptune) para reunir fondos para la compra y protección de grandes extensiones de estos Heritage Coasts. Actualmente esta entidad es propietaria de unos $820 \mathrm{Kms}$. de litoral (Raikes, 1990). Se permite el acceso del público a estas áreas, pero, en virtud de su propiedad, la entidad puede impedir los desarrollos que no son apropiados y fomentar medidas de conservación más efectivas.

Otros tipos de espacios protegidos son las National Nature Reserves y los SSSIs. Ya existen más de 200 de las primeras, que cubren unas 160.044 ha, y algo menos de 5.000 de los últimos, con una extensión total de 1.517,53 ha. Como se señaló anteriormente en el cuadro II, esta protección adicional, administrada por la Nature Conservancy Council, cubre extensas áreas dentro de los Parques Nacionales. Sin embargo, a diferencia de la Countrys Commission, el Nature Conservancy Council es un organismo propietario de tierras; posee y administra sus propias reservas naturales. Además es responsable de la declaración y administración de las $A O N B s$, aunque éstas pueden seguir siendo de propiedad privada.

El papel del Nature Conservancy Council en este contexto es conseguir acuerdos administrativos con los propietarios. Como se verá en la próxima sección, esto ha sido fuente de graves problemas. Esta función la ejercen equipos regionales de administradores (8 en Inglaterra y 3 en Gales), la mayoría de los cuales son científicos naturales, aunque el Consejo está asistido en su trabajo por académicos y organizaciones voluntarias para la conservación.

La categoría final de áreas protegidas tiene su origen en la legislación europea, específicamente en el Reglamento del Consejo (CEE) núm. 797/85, que autorizaba a los Estados Miembros a poner en marcha proyectos nacionales especiales en las Environmentally Sensitive Areas (Arcas Ambientalmente Vulnerables); dichas Areas se consideran de gran importancia desde el punto de vista ecológico o paisajístico. Pueden disponer de ayudas los agricultores que se compro-

$$
-159-
$$


metan a cultivar tales áreas de forma que conserven o mejoren su calidad ambiental. Los agricultores deben garantizar que el número de reses y el nivel de intensidad agrícola sean compatibles con las necesidades ambientales del área. Se han designado seis Areas de este tipo en Inglaterra y Gales y dos más en Escocia. En 1988, el número aumentó a 12 (Blunden and Curry, 1988). Los agricultores reciben pagos por indemnización en función de características tales como tierras para pastos, setos vivos, muros de piedra, arboledas y edificaciones. Lo que se pretende con estas medidas es salvaguardar las características de los paisajes y de la flora y la fauna, así como las características arqueológicas de cada área. La declaración de tales áreas es responsabilidad del gobierno central.

Por consiguiente, son seis las principales categorías de áreas oficialmente protegidas. Estas se han resumido en el cuadro III. La Countryside Commission y el Nature Conservancy Council son los principales organismos encargados de la conservación del medio ambiente. Sin embargo, hay que insistir en que el papel de otras agencias tales como las autoridades locales y organismos voluntarios (por ejemplo, la $N a$ tional Trust) es también muy importante en relación con la protección del medio ambiente (Tunbridge, 1981). Debido a su larga historia y dimensión, dicha entidad constituye el principal ejemplo de tales organismos. Se trata de una organización voluntaria cuya condición de sociedad benéfica la exime de impuestos, aunque se puede beneficiar de fondos del gobierno central administrados por la Countryside Commission o bien por el Nature Conservancy Council. Esta entidad adquiere tierras y propiedades mediante la compra de la propiedad en cuestión, así como a través de legados, muchos de los cuales los hacen herederos de anteriores propietarios con el fin de evadir el pago de impuestos sobre sucesiones. Esta organización (la National Trust) ya cuenta con más de 2.500 .000 socios, quienes contribuyen a sus ingresos y a los gastos de administración de sus propiedades; actualmente dicha entidad tiene en propiedad unas 228.713 hectáreas de tierra y además tiene derechos de protección sobre unas 31.402 hectáreas más (Groome, 1993). Todo esto constituye algo más del $1 \%$ de la superficie total de Gran Bretaña; incluye extensiones importantes dentro de los Parques Nacionales y las Heritage Coasts. Así pues, queda patente la importancia de esta entidad protectora, tanto en el contexto de la conservación como en el de la provisión de áreas recreativas. 


\begin{tabular}{|c|c|c|}
\hline \multicolumn{3}{|c|}{ Cuadro III } \\
\hline CATEGORIAS Y & DEFINICIONES DE & ESPACIOS PROTEGIDOS \\
\hline Categoría & Designado por & Definición \\
\hline Parque Nacional & $\begin{array}{l}\text { Countryside Commission } \\
\text { (Comisión del Campo) }\end{array}$ & $\begin{array}{l}\text { Area de gran belleza y espacio relativa- } \\
\text { mente silvestre para beneficio de la na- } \\
\text { ción: } \\
\text { i) Las características de la belleza del } \\
\text { paisaje son estrictamente conservadas. } \\
\text { ii) Se facilitan acceso e instalaciones de } \\
\text { recreo para el público, al aire libre. } \\
\text { iii) Se protegen flora, fauna, construc- } \\
\text { ciones y lugares de interés histórico y } \\
\text { arquitectónico. } \\
\text { iv) Se mantiene el uso de la agricultura } \\
\text { establecida. }\end{array}$ \\
\hline $\begin{array}{l}\text { Areas of Outstanding Natu- } \\
\text { ral Beauty (AONBs) (Areas } \\
\text { de gran belleza natural) }\end{array}$ & Countryside Commission & $\begin{array}{l}\text { Zonas rurales que carecen de extensas } \\
\text { áreas abiertas aptas para el recreo y } \\
\text { estatus de parque nacional; son sin em- } \\
\text { bargo, de tal belleza que existe interés } \\
\text { tanto nacional como local para su pro- } \\
\text { tección. }\end{array}$ \\
\hline $\begin{array}{l}\text { Coastal Heritage } \\
\text { (Patrimonio costero) }\end{array}$ & Countryside Commission & $\begin{array}{l}\text { Una designación no autorizada cubre } \\
\text { áreas seleccionadas de litorales no de- } \\
\text { sarrollados. }\end{array}$ \\
\hline $\begin{array}{l}\text { Environmentally Sensitive } \\
\text { Areas } \\
\text { (Areas ambientalmente } \\
\text { vulnerables) }\end{array}$ & Ministro de Agricultura & $\begin{array}{l}\text { Areas de importancia ambiental nacio- } \\
\text { nal cuya conservación depende de la } \\
\text { adopción, mantenimiento o extensión } \\
\text { de una forma específica de agricultura, } \\
\text { en la cual posibles cambios en las prác- } \\
\text { ticas agrícolas amenazan seriamente el } \\
\text { medio ambiente }\end{array}$ \\
\hline $\begin{array}{l}\text { Sites of Special Scientific } \\
\text { Interest (SSSIs) } \\
\text { (Sitios de especial interés } \\
\text { científico) }\end{array}$ & $\begin{array}{l}\text { Nature Conservancy Council } \\
\text { (Consejo para la Conserva- } \\
\text { ción de la Naturaleza) }\end{array}$ & $\begin{array}{l}\text { Cualquier área de tierra que sea de es- } \\
\text { pecial interés por razón de su flora, fau- } \\
\text { na, o características geológicas o fisio- } \\
\text { gráficas. }\end{array}$ \\
\hline $\begin{array}{l}\text { Reservas naturales } \\
\text { nacionales }\end{array}$ & Nature Conservancy Council & $\begin{array}{l}\text { Tierras de importancia nacional que } \\
\text { son administradas como reservas natu- } \\
\text { rales por el Nature Conservancy Council, } \\
\text { bajo un acuerdo con el mismo o con } \\
\text { una organización oficial. }\end{array}$ \\
\hline
\end{tabular}

FUENTE: Elaboración propia. 
En resumen, como ha observado Curtis (1991:457) «... la protección del paisaje en el Reino Unido depende de las actividades de un complejo de organismos, entre los que figuran el gobierno nacional, las administraciones locales, organismos gubernamentales autónomos y organizaciones voluntarias». Aunque en Gran Bretaña la legislación destinada a promover la protección ambiental tiene una larga historia, esta misma «longevidad» es en gran medida causa de una complejidad que representa ya uno de los principales problemas para la protección de los paisajes naturales.

\section{Algunos problemas actuales}

Complejidad del sistema. Quizás el primer y más obvio punto a debatir en el contexto de los problemas con que se enfrentan los paisajes protegidos de Inglaterra y Gales es la misma complejidad del sistema que, se supone, realiza esta protección. Se ha argumentado que «... en un país donde la mayoría de la tierra es propiedad privada y es utilizada por la población para ganarse la vida, la propiedad estatal no es una respuesta adecuada; la protección tiene que lograrse de formas más sutiles» (Poore and Poore, 1987:5). Esto, desde luego, plantea preguntarse hasta qué punto pueden ser efectivas tales intervenciones «sutiles» y si el sistema, en su evolución, ha perdido claridad de objetivos en su afán por contener presiones «sutiles», convirtiéndose en el más ineficaz. Al nivel más fundamental, el control del desarrollo a través del sistema de planificación sigue siendo el principal instrumento mediante el que se logra la protección de los paisajes. Sin embargo, es evidente que el cambio del paisaje no es un factor del desarrollo físico, sino más bien un resultado de la gestión del paisaje. En este sentido es donde el sistema británico para la protección ambiental puede considerarse inadecuado, puesto que lo único que ofrece para la correcta gestión del espacio es un sistema complejo y poco sistemático de incentivos, disponibles en algunas áreas pero no en otras, y susceptible de ciertas manipulaciones por parte de los beneficiarios y sus asesores financieros.

El sistema británico tiende a favorecer los criterios de los habitantes urbanos -fenómeno quizás comprensible en un país que fue el primero en experimentar las consecuencias urbanas de la revolución 
industrial-, pero se trata de una tendencia que ha conducido a una sobreconcentración en los problemas de urbanización a expensas de aspectos más amplios relativos al cambio paisajístico. Así que, en un país que se ha adherido con entusiasmo al estilo de producción capitalista, la toma de decisiones sobre la tierra -y especialmente su administración- ha llegado a ser considerada prerrogativa de los propietarios individuales. Sin embargo, al formular una serie de políticas, cuyo objetivo, por lo menos en apariencia, es promover un acceso más amplio y un mayor disfrute del paisaje británico, los sucesivos gobiernos británicos han emprendido un camino que a la fuerza iba a ocasionar conflictos entre propietarios y otros usuarios potenciales. En un intento de abordar este conflicto, más que de resolverlo, se ha introducido una compleja serie de medidas, dando lugar a una situación donde se nota claramente la falta de una política firme $\mathrm{y}$ donde las pocas medidas que se han tomado han sido en su mayor parte respuestas improvisadas.

En esta interpretación de la política de protección ambiental en Gran Bretaña, la aparente complejidad no se considera una respuesta «sofisticada» a las inevitables limituciones de una democracia moderna; más bien es el resultado de muchos años eludiendo de problemas fundamentales (Adams, 1986). Es tal vez significativo, aunque decepcionante, que algunas de las recomendaciones del más reciente estudio oficial de las políticas de Parques Nacionales no fueran aceptadas por el gobierno. La Countryside Commission decidió celebrar el cuadragésimo aniversario de la aprobación de la National Parks and Acces to the Countryside Act (Ley de los Parques Nacionales y del Acceso al Campo), con un análisis oficial de sus políticas (Edwards, 1991). En el informe Fit for the Future (Aptos para el Futuro) se proponía que, dentro de las áreas de los Parques Nacionales, se debian delegar las funciones de gestión y administración del Nature Conservancy Council y de otros organismos, tales como el English Heritage (Patrimonio Inglés), en las autoridades de los Parques Nacionales. En otras palabras, la responsabilidad de las Reservas Naturales, los SSSIs y los monumentos arqueológicos e históricos recaería en una sola agencia. No cabe duda de que ésto simplificaría una serie de negociaciones excesivamente complejas situándolas dentro de los Parques Nacionales. Sin embargo, la respuesta del gobierno fue negativa: argumentaba que «... en la actualidad, en la mayoría de los casos, esto no es factible» (Department of the Environment, 1992: 4).

$$
-163-
$$


Esta respuesta tímida es típica de lo que, según se ha argumentado, representa una grave reducción del interés gubernamental, a principios de los años 90 en los Parques Nacionales, reflejada también en la reducción en términos reales de los recursos financieros (Phillips, 1993). Sin embargo, la incapacidad de resolver la complejidad de las disposiciones para la protección de los paisajes ambientalmente vulnerables en las Islas Británicas se debe también a las rivalidades existentes en este campo entre los Ministerios del gobierno. Aunque el Ministerio del Medio Ambiente es el Ministerio involucrado clave, otros ministerios tales como Agricultura, Defensa, Comercio y Transporte e Industria también tienen interés en cualquier legislación que pueda restringir la urbanización, influir el uso privado de la tierra o promover un criterio de protección ambiental más acorde con principios de sustentabilidad que con el crecimiento económico a corto plazo. En el Reino Unido se ha creado un sistema complejo de protección ambiental debido a los muchos grupos de intereses, existentes incluidos los ministerios del gobierno. El fracaso para simplificar el sistema se debe en realidad a la incapacidad de resolver tal conflicto y de decidir si el paisaje británico es simplemente uno entre varios factores de producción, o si es un «bien público» al cual se deberían aplicar principios de sustentabilidad.

Principales organismos. No cabe duda de que los principales organismos responsables de la protección ambiental de los paisajes afrontan dificultades considerables. Por ejemplo, la Countryside Commis sion debe conciliar su responsabilidad, por un lado, de promover el recreo general del público en el campo y, por otro, de conservar las áreas ambientalmente vulnerables (Cripps, 1980). En general, esta última debe predominar, pero las limitadas competencias reales concedidas a la Comisión así como sus recursos limitados, con frecuencia disminuyen su efectividad. En consecuencia, aquélla se ve obligada a funcionar mediante canales informales y a lograr tantos acuerdos voluntarios como sea posible. Muchas situaciones dependen en realidad de las cualidades personales de sus empleados y de su habilidad para persuadir a los propietarios de la conveniencia de adoptar una acción alternativa. Por este motivo, la Comisión no siempre tiene éxito en el logro de sus objetivos. Por ejemplo, en su memoria anual de 1992-93, la Comisión reconocía que en relación con las $A O N B s$, «la acción positiva para la conservación de estas áreas

$$
-164-
$$


ha estado limitada por presiones financieras» (Countryside Commission, 1993).

Aunque el Nature Conservancy Council (English Nature) sí tiene competencias, por ejemplo, en cuanto a la propiedad de tierra, éste afronta problemas en su funcionamiento parecidos a los de la Countryside Commission. El Consejo nunca ha vacilado en su llamamiento a favor de una estrategia nacional para el uso de la tierra, porque en su opinión «... la política actual de conservación aislada en reservas separadas fracasará debido a su carácter fragmentario y adicional» (Open University, 1985: 33). Esta petición no ha sido atendida y es evidente que este organismo carece de confianza en su propia capacidad para ejecutar su función en el marco del sistema actual. Los recursos disponibles para que el Nature Conservancy Council efectúe pagos de indemnización relacionados con los SSSIs o para comprar fincas enteras y crear National Nature Reserves son limitados, como lo es su capacidad para "vigilar» la efectividad de tales disposiciones (Adams, 1986; Evans, 1992).

El tercer grupo involucrado en la protección ambiental de los paisajes está formado por las comisiones ejecutivas de los Parques Nacionales. Una crítica constante a estas autoridades es su incapacidad de adoptar una visión estratégica a largo plazo para su área de responsabilidad. Para las autoridades de los Parques Nacionales, los intereses locales tienden a prevalecer sobre el supuesto interés nacional de los mismos (Green, 1981: 49). La composición de las autoridades de los Parques es significativa a este respecto. Dos terceras partes de sus miembros son nombramientos locales y la otra tercera parte la nombra el Ministro. No es de extrañar que normalmente los intereses agrarios estén muy bien representados. Por ejemplo, en 1985 agricultores y propietarios ocupaban una tercera parte de los cargos en los tres Parques Nacionales galeses y, al mismo tiempo, casi más del $40 \%$ de los miembros nombrados por el Ministro eran agricultores o propietarios (Owen, 1990). Desde 1979 los miembros con «experiencia en agricultura y actividades relacionadas» han aumentado a nivel nacional en un 50\%. Aunque oficialmente las autoridades dan más prioridad a la conservación del paisaje que al acceso recreativo cuando los dos están en conflicto, el hecho de que la agricultura es de por sí un factor cada vez más importante en el cambio del paisaje sigue siendo un tema pendiente de abordar de 
forma eficaz (Open University, 1985). Mientras los intereses agrarios tengan tal poder de representación en los Parques Nacionales, es probable que ésto siga siendo un problema considerable.

La posición de las autoridades de los Parques Nacionales ha sido también más difícil en los últimos años debido al desarrollo de políticas en otras áreas. La tendencia general de la política del gobierno puede haber servido para reducir de forma significativa el acceso a áreas dentro del Parques Nacionales y a otras áreas de gran atractivo paisajístico utilizadas para recreo. Mientras la política oficial de los Parques Nacionales continúe como ahora regulando tanto el uso recreativo público como la conservación, el desarrollo de políticas en otros ámbitos puede obstaculizar ese objetivo. La privatización ha sido una constante de la política gubernamental durante los años 80 y 90. Esto ha afectado a algunas áreas dentro de los Parques Nacionales así como a otras zonas rurales, como consecuencia, principalmente, de la privatización del agua y de la Forestry Commission (Comisión Forestal). Mientras estos organismos eran nacionales, estaban obligados a facilitar acceso público a áreas bajo su jurisdicción. Sin embargo, cuando se convierten en organismos privados se suspende tal obligación. Desde 1981 se han vendido más de 250.000 acres de bosque pertenecientes a la Forestry Commission (Spink, 1994) y parece probable que los propietarios intenten impedir el libre acceso a zonas donde anteriormente el público podía caminar. De igual forma, cada vez es más frecuente que los propietarios de lugares importantes como cascadas cobren a los visitantes.

La cuarta gran contribución a la protección ambiental de los paisajes en Gran Bretaña la aporta el sector voluntario, en particular organismos tales como la National Trust. Esta es famosa por su administración de edificios históricos y tierras asociadas, pero con la expansión del uso recreativo rural ha estado sometida a la presión creciente de numerosos visitantes, no reaccionando siempre de forma positiva (Lowe, and Goyder, 1983). De hecho, esta entidad se enfrenta con el mismo dilema que la Countryside Commission, en su intento de adaptarse a la gran demanda de esparcimiento mientras intenta proteger los edificios y las tierras (Groome, 1993). Desgraciadamente, es claramente elitista en su estructura y toma de decisiones. Aunque para su financiación depende de sus socios ordinarios, durante muchos años los ha considerado sólo como visitantes de sus monu- 
mentos, demostrando con frecuencia poco interés en asumir sus responsabilidades; un buen ejemplo de esta postura fue su decisión de arrendar tierras a la OTAN en Brackenham (Buckinghamshire) para la construcción de un refugio. Sin embargo, más recientemente, tras la polémica surgida a raíz de ésto y por la presión de sus afiliados, la National Trust ha demostrado una mayor conciencia de su responsabilidad hacia sus socios.

Densidad demográfica. Mientras conviene recordar que el actual sistema británico para la protección del paisaje consta de una serie de políticas que son, en el fondo, insustentables, es preciso reconocer también las limitaciones dentro de las cuales ha evolucionado dicho sistema. La primera de éstas es el hecho de que las Islas Británicas constituyen una de las zonas más densamente pobladas del mundo (más de 240 habitantes por kilómetro cuadrado). En términos estrictos, pues, la presión demográfica sobre la tierra disponible es considerable y, dado el romanticismo de muchos habitantes urbanos británicos hacia los ambientes rurales, las presiones psicológicas para «renovar» (aunque superficialmente) sus vínculos con las áreas rurales son quizás comprensibles. Sin embargo, es en los Parques Nacionales donde los conflictos resultantes de tales presiones alcanzan su máxima expresión. En este contexto, es preciso recordar que los Parques Nacionales de Inglaterra y Gales son espacios dentro de los cuales vive y se gana la vida un número sustancial de personas y donde predomina la posesión de tierras y otras propiedades (Busch, 1973) (Cuadro IV).

Así, la idea de, por un lado, intentar promover el esparcimiento en el campo para el público en general y, por otro, tratar de promover la ética de la conservación del paisaje es sumamente problemática en un país tan densamente poblado como Gran Bretaña. Esto viene agravado por la relativa proximidad de muchos Parques Nacionales a importantes centros de población. Las autopistas o las principales carreteras pasan muy cerca de muchos de ellos. Por ejemplo, aprovechando la M6 se puede llegar al Lake District en menos de una hora desde las aglomeraciones urbanas de Manchester y Merseyside. Igualmente, el Peak District está rodeado de cuatro de estas zonas, a saber Manchester, West Yorkshire y las Midlands (Este y Oeste). Como resultado, la densidad de visitantes es muy alta, produciendo una presión considerable sobre el espacio. Tanto el 


\section{CUAdRo IV}

PARQUES NACIONALES: DENSIDAD DE POBLACION, VISITANTES Y PROPIEDAD DE LA TIERRA

\begin{tabular}{|c|c|c|c|}
\hline Nombre & $\begin{array}{c}\text { Densidad de } \\
\text { población } \\
\left(\mathrm{N} .^{\circ} \text { hab. por } k m 2\right)\end{array}$ & $\begin{array}{l}\mathrm{N}^{\circ} \text { visitantes/ } \\
\text { año por } \mathbf{k m}^{2}\end{array}$ & $\begin{array}{c}\text { \% propiedad } \\
\text { privada sobre } \\
\text { superficie total }\end{array}$ \\
\hline Brecon Beacons .......... & 23.9 & 5185 & 69.6 \\
\hline Dartmoor .................. & 30.8 & 8466 & 57.3 \\
\hline Exmoor ..................... & 14.6 & 4373 & 79.1 \\
\hline Lake District .............. & 17.5 & 8772 & 58.9 \\
\hline Northumberland .......... & 2.1 & 970 & 56.4 \\
\hline North York Moors ....... & 61.6 & 25114 & 79.9 \\
\hline Peak District ............... & 26.6 & 14245 & 72.3 \\
\hline Pembrokeshire Coast ... & 39.5 & 22298 & 85.7 \\
\hline Snowdonia ................. & 11.0 & 3687 & 69.9 \\
\hline Yorkshire Dales .......... & 10.6 & 5114 & 96.2 \\
\hline
\end{tabular}

Fuente: Countryside Commission (1993).

Lake District como el Peak District reciben más de 20 millones de visitantes al año. Sin embargo, la presión de los visitantes sobre el espacio disponible es considerablemente superior en los Parques más pequeños, tales como el North York Moors y la Pembrokeshire Coast (Cuadro IV). Es en estos Parques donde se presentan las mayores dificultades para absorber a tantos visitantes. Asimismo, las relaciones entre visitantes y residentes locales, y entre visitantes y cantidad de tierra de propiedad privada, son un indicador del alto grado de conflicto que puede surgir dentro de los diferentes Parques (Cuadro V).

Así, aunque Northumberland es uno de los Parques menos visitados con sólo un millón de visitantes anuales, en realidad la relación de visitantes/residentes locales es bastante alta. El Lake District, el Peak District y la Pembrokeshire Coast se confirman como las áreas de mayor presión visitantes/residentes. Sin embargo, la relación entre el número de visitantes y la cantidad de tierra de propiedad privada varía enormemente entre los diez Parques. Esta medida puede generar un índice de posible conflicto entre los que acuden a los Parques por motivos recreativos y los que de hecho son propietarios de los recursos que los visitantes quieren disfrutar. Así pues, por cada

$$
-168-
$$




\section{Cuadro V}

PARQUES NACIONALES: DENSIDAD DE POBLACION, VISITANTES Y PROPIEDAD DE LA TIERRA

\begin{tabular}{|c|c|c|}
\hline Nombre & $\begin{array}{c}\text { Residentes: } \\
\text { visitantes (año) }\end{array}$ & $\begin{array}{c}\text { N. } .^{0} \text { visitantes } / \text { año } \\
\text { por } \mathrm{km}^{2} \text { de } \\
\text { tierra privada }\end{array}$ \\
\hline Brecon Beacons ................... & $1: 217$ & 7447 \\
\hline 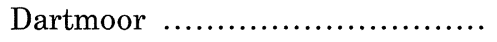 & $1: 275$ & 14787 \\
\hline Exmoor $\ldots \ldots \ldots \ldots \ldots \ldots \ldots \ldots \ldots \ldots$ & $1: 300$ & 5525 \\
\hline Lake District ..................... & $1: 500$ & 14892 \\
\hline Northumberland .................... & $1: 454$ & 1721 \\
\hline North York Moors ................. & $1: 407$ & 31429 \\
\hline Peak District ...................... & $1: 535$ & 19704 \\
\hline Pembrokeshire Coast .............. & $1: 565$ & 26000 \\
\hline Snowdonia ........................... & $1: 336$ & 5274 \\
\hline Yorkshire Dales .................... & $1: 484$ & 5316 \\
\hline
\end{tabular}

Fuente: Countryside Commission (1993).

kilómetro cuadrado de tierra privada en el North York Moors, hay anualmente más de 30.000 visitantes; 26.000 en la Pembrokeshire Coast y casi 20.000 en el Peak District. Aunque estas cifras contribuyen a facilitar una indicación valiosa de la variación en el posible grado de conflicto entre los Parques Nacionales, el conflicto se manifiesta a una escala más local.

El conflicto a escala local. Como indica el cuadro IV, un número elevado de personas viven dentro de los Parques Nacionales y, aun cuando la media de edad tiende a ser más elevada que el promedio nacional, una proporción considerable de tales personas encuentra empleo dentro o muy cerca de las áreas de los Parques Nacionales. $\mathrm{Su}$ bienestar económico, por tanto, está vinculado al éxito de la agricultura, el turismo, la explotación de canteras, o la explotación forestal. Para muchos visitantes, el principal propósito de su visita es disfrutar de la tranquilidad del campo. Para los habitantes locales, la supervivencia económica de sus comunidades puede depender de una serie de actividades que exigen una explotación activa de la tierra y de otros recursos. Los visitantes, por su parte, parecen estar más orientados hacia la conservación de tales recursos. El cuadro VI intenta resumir algunos de los conflictos que surgen en áreas rurales. 


\section{CuAdro VI}

\section{CONFLICTOS CAUSADOS POR EL USO DE LA TIERRA EN EL AREA RURAL}

\begin{tabular}{|c|c|c|}
\hline Uso de la tierra & Requerimientos & Conflictos pontenciales \\
\hline Agricultura ........... & $\begin{array}{l}\text { Area extensa; no acceso; } \\
\text { actividad lucrativa }\end{array}$ & $\begin{array}{l}\text { Cambios en el espacio; dere- } \\
\text { chos de acceso; métodos mo- } \\
\text { dernos de agricultura; conta- } \\
\text { minación; intrusión visual }\end{array}$ \\
\hline Excavación & $\begin{array}{l}\text { Minerales; actividad lucra- } \\
\text { tiva; acceso al mercado }\end{array}$ & $\begin{array}{l}\text { Destrucción del espacio; } \\
\text { tráfico concurrido; ruido; } \\
\text { polvo; intrusión visual }\end{array}$ \\
\hline Explotación forestal ... & $\begin{array}{l}\text { Area extensa; suelos } \\
\text { propicios }\end{array}$ & $\begin{array}{l}\text { Tierra estéril; acceso limi- } \\
\text { tado; destrucción del medio } \\
\text { ambiente: espacio visual- } \\
\text { mente alterado }\end{array}$ \\
\hline Agua & $\begin{array}{l}\text { Cuencas no contamina- } \\
\text { das, exclusividad de uso }\end{array}$ & $\begin{array}{l}\text { Derechos de acceso; habi- } \\
\text { tats perdidos; regulación de } \\
\text { ríos }\end{array}$ \\
\hline Energía cinética .... & $\begin{array}{l}\text { Lugares altos (skylines } \\
\text { sites) }\end{array}$ & intrusión visual \\
\hline Turismo ............ & $\begin{array}{l}\text { Acceso; infraestructura; } \\
\text { provisión de servicios }\end{array}$ & $\begin{array}{l}\text { Uso estético vs mecaniza- } \\
\text { do; objetivos individuales } \\
\text { vs masa; no estacional; res- } \\
\text { tricciones de conservación }\end{array}$ \\
\hline Alojamiento .... & $\begin{array}{l}\text { Tierra; infraestructura } \\
\text { desarrollada; servicios }\end{array}$ & $\begin{array}{l}\text { Vías y tráfico; conservación } \\
\text { de costas; competencia por } \\
\text { alojamiento; fricciones en- } \\
\text { tre locales y visitantes }\end{array}$ \\
\hline
\end{tabular}

Adaptado de Spink (1994).

Sin embargo, los mismos visitantes no constituyen un grupo homogéneo y sus demandas sobre áreas tales como los Parques Nacionales son muy diferentes. Recientemente se han ampliado dichas demandas, especialmente con el crecimiento de actividades al aire 
libre, tales como el esquí acuático, vuelo ultraligero, rallye y motocross.

Estas actividades, en sí mismas, pueden entrar en conflicto con la opinión de personas -tales como caminantes, observadores de aves y artistas, por ejemplo- cuyo criterio sobre el medio ambiente de los Parques es más estético. Tales conflictos se han registrado en Windermere en el Lake District (el esquí acuático y la pesca frente a los paseos tranquilos en bote); en la senda de largo recorrido del Ridgeway en el sur de Inglaterra (caminantes y jinetes frente al tráfico motorizado, en algunos tramos); y las Norfolk Broads (principalmente la pesca frente a las lanchas motoras). Estos conflictos pueden ser algo más complicados entre aquéllos que practican actividades excluyentes que entre los que practican actividades compatibles, como pescadores y excursionistas en lanchas. Aun para los dedicados a la misma actividad (por ejemplo, paseos en lanchas) existiría conflicto en función de si los interesados son individuos particulares que ejercen con regularidad esta actividad o si son sólo aficionados que alquilan el servicio esporádicamente.

Naturalmente, organismos tales como la Countryside Commission y las autoridades de los Parques Nacionales han prestado mucha atención al intento de resolver tal conflicto. En general, se ha utilizado el mecanismo de planificación para dirigir actividades específicas a zonas concretas y mantener separadas las actividades que no son compatibles. La creación deliberada de los honey pots para atraer a la mayor cantidad posible de personas a fin de liberar presión en las zonas más lejanas ha sido la política adoptada con más frecuencia. Así, lugares tales como Bowness en el Lake District y Matlock Bath en el Peak District han desarrollado una amplia gama de diversiones populares y de instalaciones de recreo. De naturaleza diferente, pero similares en su concepción, son lugares tales como Grasmere en el Lake District y Housesteads en Hadrian's Wall en el parque de Northumberland, donde los centros de interpretación, atraen a gran número de personas y las «alejan» de las áreas más remotas.

Sin embargo, tal concentración puede ocasionar sus propios problemas. Este es el caso concreto de áreas como Hadrian's Wall en Northumberland, de sendas de largo recorrido tales como el Pennine Way, y de áreas populares de alpinismo como Malham Cove en los Yorkshire Dales y Dovedale en el Peak District. El gran número de

$$
-171-
$$


personas atraídas a estos espacios en sí mismo, ocasiona daños físicos importantes; por ejemplo, cada año dos millones de personas caminan en las zonas fácilmente accesibles del sur de Dovedale. Sin embargo, el daño ecológico no se limita a las áreas de más fácil acceso. Como ilustración de esto tenemos, por ejemplo, la Three Peaks Walk (Travesía de los Tres Picos) (Whernside, Ingleborough y Pen-y-Gent) en la parte montañosa norte de los Yorkshire Dales, la cual es utilizada anualmente por 15.000 personas. La ruta de ascenso a Ingleborough tiene ahora unos 40 metros de ancho. De forma similar, el Monte de Snowdon en el norte de Gales atrae a 250.000 personas al año; su cima y sus sendas de acceso están bastante erosionadas. La reparación y construcción de sendas constituyen una gran parte de las labores efectuadas por las autoridades locales y por los consejos de administración de los Parques Nacionales; a menudo estas actividades exigen importantes proyectos de ingenieria civil. Más importante es la posibilidad real de que la presión ejercida por los numerosos visitantes pueda dañar fundamental e irreversiblemente aspectos históricos del paisaje. Entre éstos están Stonehenge y Hadrian's Walls. El primero es visitado por más de 500.000 personas al año, aunque, para su protección, ha sido cercado y el público sólo tiene acceso mediante un paso subterráneo construido bajo la carretera nacional A844, conectada a un amplio aparcamiento.

Las áreas rurales atractivas de Inglaterra y Gales no han estado al margen de los procesos de cambio que, a mayor escala, afectan al resto del Reino Unido. Los procesos sociales y económicos que operan a escala nacional han producido un cambio importante a escala local. El aislamiento relativo de muchas de las áreas protegidas, especialmente de los Parques Nacionales, es responsable del limitado nivel de oportunidades de empleo a escala local. A su vez, esto impulsa la emigración de los residentes locales más pobres. Por otra parte, la vivienda dentro de un Parque Nacional es atractiva para muchas personas acomodadas que disponen de vehículo. Estos procesos han acarreado un cambio social importante a nivel local (Newby, 1988), especialmente cuando el nivel de precios de las casas locales va aumentando por la presión de la demanda de dichos «forasteros» acomodados. Por consiguiente, los residentes locales no son competitivos en el mercado de la vivienda local. 
El Lake District facilita una ilustración interesante de algunas de las dificultades experimentadas en este proceso y de las políticas abordadas para intentar resolver algunos de los problemas observados. El área tiene unas 17.000 viviendas de las cuales se ha calculado que un $11 \%$ corresponde a segundas viviendas. En algunos lugares la proporción sobrepasa el 30\% (Clark, 1982). La preocupación por la tasa de crecimiento de las segundas viviendas y la falta de competitividad de los residentes locales (a mediados de los 70 se calculaba que los precios de las casas oscilaban entre 2.000 y 6.000 libras esterlinas más dentro del Parque que fuera del mismo) condujeron a la adopción de una política de «viviendas para los locales». El objetivo de esta política fue restringir la construcción a solo aquéllas que satisficieran las necesidades locales. Así se intentaba aliviar los problemas de los residentes locales (principalmente de los jóvenes) para comprar viviendas adecuadas. Sin embargo, esto desvió la atención de los «inmigrantes» hacia las viviendas ya existentes que estaban al margen de esta política. Como resultado, la tasa de incremento de los precios de la vivienda se elevó espectacularmente. Al mismo tiempo, aunque las nuevas viviendas estaban restringidas a los residentes locales, esto no garantizaba que tales individuos pudieran pagar los precios de residencias totalmente nuevas. Muchos residentes locales tienen puestos de trabajo relativamente mal remunerados, y muchos de los que buscan vivienda, por ejemplo parejas jóvenes, probablemente no cuentan con los ahorros suficientes. Así pues, los beneficios de esta política han sido algo limitados. La Housing Act (Ley de Vivienda) de 1980 hizo aun más difícil la situación para los residentes locales con recursos limitados, pues obligó a las autoridades locales a vender casas del Estado a los actuales arrendatarios que deseaban comprarlas. Como los descuentos concedidos eran considerables, de hecho se vendieron muchas de estas casas (Malpass, 1980). Sin embargo, esta ganancia a corto plazo de los compradores se logró a expensas de la pérdida a largo plazo de viviendas rurales de alquiler más baratas.

Un estudio sobre la presión del desarrollo en los Parques Nacionales realizado en los años 80 demostraba que la tendencia, medida por el número de solicitudes de permisos de construcción era creciente. Pero la proporción de autorizaciones concedidas frente a autorizaciones denegadas fue más baja dentro de las áreas del Parque 
que en el resto de Inglaterra y Gales (Curry, 1989). En términos generales, esto parece apoyar la tesis de que el objetivo de conservación de los Parques se confirma y pesa más, por ejemplo, que el desarrollo de su función recreativa. En algunos casos importantes -y espectaculares- la batalla por la conservación se ha perdido. Los más importantes se relacionan con centrales eléctricas, explotaciones mineras, construcción de carreteras y uso de extensas áreas de algunos Parques Nacionales con propósitos de adiestramiento militar.

Uno de los primeros y más graves retrocesos en la batalla por la conservación tuvo lugar en Snowdonia, donde en los años 60 se construyó la central de energía nuclear de Trawsfynydd en contra de una gran oposición. Se excavaron 3.800 metros cúbicos y, a pesar de los intentos de atenuar el impacto de las obras, la central representa claramente una «intrusión incongruente y dominante en el paisaje de Snowdonia» (Owens, 1990: 127). El mismo comentario podría aplicarse a la construcción de la estación de Fylingdales (sistema de alarma anticipada) situada en los North York Moors. Otro conflicto algo mayor surge por las explotaciones mineras que se realizan en los Parques Nacionales. Desafortunadamente, algunas de las formaciones geológicas más valiosas desde un punto de vista económico son también elementos de los paisajes más atractivos. La excavación de canteras dentro de los Parques Nacionales es muy problemática, no sólo porque desfiguran el paisaje, sino también porque crean altos niveles de contaminación debida al polvo y al ruido. Aún más negativos son los volúmenes de tráfico pesado que estas canteras originan. Pero, materiales tales como la piedra caliza son vitales en la industria de la construcción y su extracción crea empleo para los habitantes de la zona. El Peak District está especialmente afectado por este problema.

Algunas de las grandes controversias y de las luchas más amargas se han librado en torno a la construcción de carreteras. Esta altera fundamentalmente la apariencia física de los paisajes «naturales» y origina también una serie de preguntas, que constituyen el campo de batalla entre sus defensores y los conservacionistas. Por ejemplo, «¿es la solución más barata necesariamente la mejor?», «¿cuál es la ruta más apropiada?», «ila carretera es realmente necesaria?». En general los conservacionistas han experimentado más derrotas que triunfos, y las actitudes del gobierno no parecen haber 
cambiado a pesar de la fuerte presión pública. «El National Parks Review Panel (Tribunal de Revisión de los Parques Nacionales) preconizaba los beneficios del transporte público. La presión pública para construir menos carreteras ha sido reconocida por el Ministro, pero no se ve reflejada todavía en la política ni en los programas» (The National Park Authority, 1993: 16).

Areas muy extensas de dos Parques Nacionales -Dartmoor y Northumberlandson, son usadas para maniobras militares. El Ministerio de defensa dispone del 14\% de Dartmoor y del 23\% del Parque de Northumberland. Esto plantea conflictos a la hora de priorizar temas tales como el hábitat de la fauna y la protección de monumentos históricos. Muchos de los desarrollos asociados con los ejercicios militares son inevitablemente impuestos por la fuerza; el ejercicio de tiro es peligroso y se imponen severas restricciones al acceso público. En el Parque Nacional de Northumberland la reciente propuesta del Ministro de Defensa de ampliar el espacio usado para ejercicios militares y por vehículos más pesados, lo cual requiere un programa amplio de construcción de carreteras, ha sido rechazada por la Countryside Commission a pesar del entusiasmo de los residentes locales por la creación de puestos de trabajo.

La agricultura y el cambio del paisaje. La principal debilidad del sistema británico de protección del paisaje radica en su preocupación por el desarrollo físico, esencialmente relacionado con la construcción. Durante los años 70 y 80 se hizo cada vez más patente que el gran desafío a la protección del paisaje en el Reino Unido no provenía del desarrollo físico de áreas anteriormente agrícolas, sino de los cambios acaecidos en la misma agricultura. Estos han acarreado cambios muy profundos en el paisaje, pero el sistema de control tiene competencias muy limitadas para enfrentarse a tales cambios. El crecimiento del número y del tamaño de las explotaciones agrícolas originó la desaparición de muros y cercas de setos vivos considerados como características emblemáticas del paisaje británico. Presiones parecidas aumentaron la demanda de construcciones agrícolas modernas en escasa armonía con el paisaje. En aras de una economía agrícola moderna y racional, se rellenaron lagunas y se drenaron tierras pantanosas, las cuales, junto con los setos, proporcionaban un hábitat importante para la fauna y la flora. En las zonas de montaña, la aplicación de argumentos económicos semejantes ha conducido al 
abandono de explotaciones agrícolas no rentables (tierras marginales), con el resultado de que los edificios agrícolas se desmoronan, los linderos de los campos se derrumban y se pone en marcha un cambio fundamental del paisaje. A menudo, la sustitución de la agricultura de montaña por la plantación de árboles ha producido una alternativa monótona y poco atractiva.

El Council for the Protection of Rural England (Consejo para la Protección de la Inglaterra Rural) ha calculado que en los últimos 40 años se ha perdido un $50 \%$ de los antiguos bosques de hoja caduca, un $50 \%$ de los pantanos y ciénagas, un $95 \%$ de los prados de flores silvestres, un $50 \%$ de los brezales de tierras bajas y un $60 \%$ de las turberas (Fig. 2). La gran mayoría de estas pérdidas se deben al cambio de las prácticas agrícolas. El Nature Conservancy Council (ahora English Nature) ha calculado que el $40 \%$ de los SSSIs es responsable del deterioro y daño de tales áreas y que sólo en 1991, un 5\% de estas superficies se perdió o perjudicó (Spink, 1994).

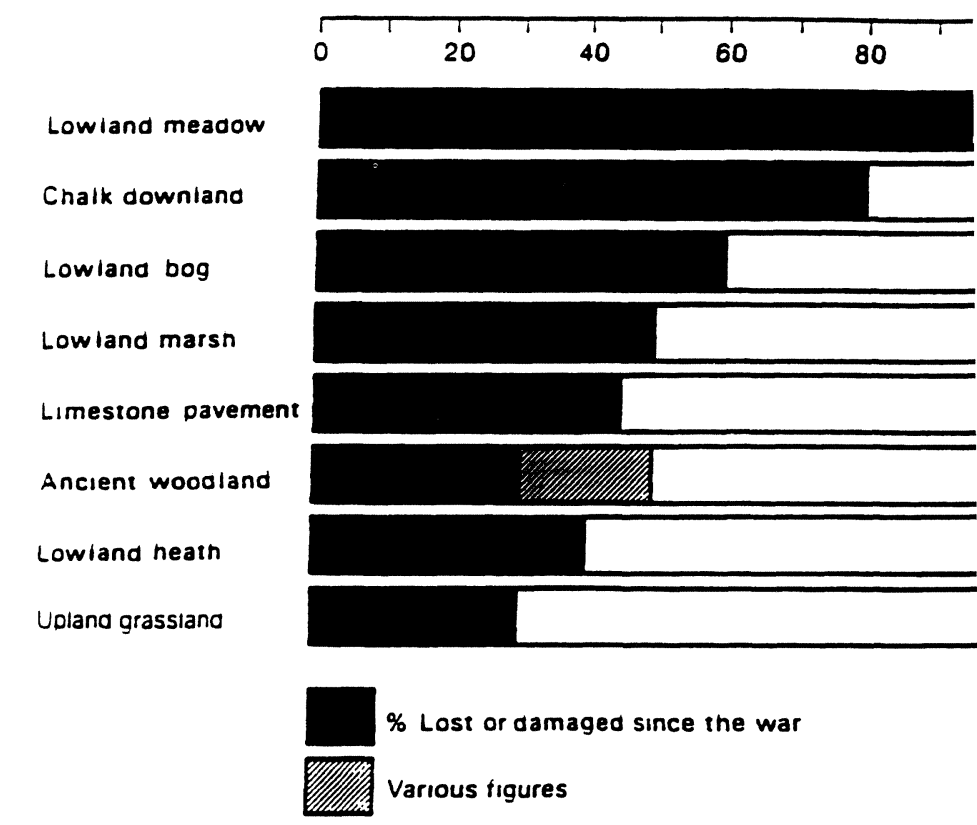

Figura 2.-Estimación de la pérdida de hábitas de flora y fauna en Gran Bretaña durante la posguerra (FUENTE: Adams, 1986). 
Con respecto al caso concreto de los Parques Nacionales, es evidente que se ha producido un cambio bastante importante en el paisaje dentro de áreas supuestamente "protegidas» (Countryside Commission 1991). El cuadro VII resume el modelo general del uso de las áreas protegidas dentro de los diez Parques durante los años 70 y 80 .

\section{Cuadro VII}

TIPOS DE PROTECCION DE LA TIERRA EN LOS PARQUES NACIONALES DURANTE LOS AÑOS 1970s Y 1980

\begin{tabular}{|c|c|c|}
\hline Tipo de protección & $\begin{array}{l}\text { Area }\left(\mathbf{k m}^{2}\right) \\
\text { en } 1970\end{array}$ & $\begin{array}{l}\text { Cambio 1970s } \\
\text { y 1980s }\left(\mathrm{km}^{2}\right)\end{array}$ \\
\hline Bosque Mixto (broadleaf/mixed woodland) & 640.5 & +9.2 \\
\hline $\begin{array}{l}\text { Bosque Alto de coniferas (coniferous high } \\
\text { forest) } \ldots \ldots \ldots \ldots \ldots \ldots \ldots \ldots \ldots \ldots \ldots \ldots \ldots \ldots\end{array}$ & 742.6 & +178.5 \\
\hline Arbustos (scrub) ........................ & 95.5 & -5.2 \\
\hline $\begin{array}{l}\text { Area aclarada/plantación nueva nuevo } \\
\text { (clear felled/newlty planted) } \ldots \ldots \ldots \ldots \ldots \ldots\end{array}$ & 279.0 & -68.9 \\
\hline 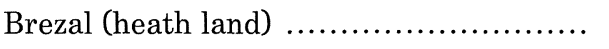 & 1392.5 & -30.9 \\
\hline Páramo brezal (grass moor) ................. & 3186.9 & -49.1 \\
\hline $\begin{array}{l}\text { Laderas en tierra alta (upland heath/ } \\
\text { grass mosaic) } \ldots \ldots \ldots \ldots \ldots \ldots \ldots \ldots \ldots \ldots \ldots\end{array}$ & 636.9 & -13.6 \\
\hline Helechos (bracken) ....................... & 667.7 & -19.2 \\
\hline Tierra cultivada (cultivaded land) ......... & 555.8 & +74.9 \\
\hline Pastos mejorados (improved pasture) .... & 3892.7 & +66.0 \\
\hline Pastos de baja calidad (rough pasture) ... & 1245.6 & -133.0 \\
\hline Agua y humedales (water and wetland) .. & 189.0 & +6.8 \\
\hline Acantilados (rock \& coastal) ............... & 211.4 & +15.2 \\
\hline Terrenos desarrollados (developed land) & 207.1 & +10.8 \\
\hline Terrenos no clasificados (unclasified land) & 68.7 & -41.4 \\
\hline
\end{tabular}

Comisión del Campo (1991). 
Así pues, dentro de la totalidad de los Parques Nacionales ha habido un cambio limitado en agua y humedales, en terrenos explotados, en zonas rocosas y costeras, y en bosques de hoja ancha y mixtos. También ha habido un importante descenso en pastos de baja calidad, páramos y brezales y en tierras aclaradas y nuevamente plantadas. Ha sido en tierras cultivadas, en bosques de coníferas altas y en pastos mejorados donde se han registrado aumentos realmente importantes. Igualmente importante es la tendencia del cambio en los linderos de los campos tradicionales. Las cercas de seto vivo han disminuido en 1.213 kilómetros (4,6\%) y los muros en 412 kilómetros (1,3\%), mientras las cercas de madera, que algunas veces reemplazan estos linderos tradicionales, se han incrementado en 346 kilómetros (5,4\%), (Countryside Commission, 1991). Así pues, resulta evidente que las tendencias generales de intensificación agrícola se han dejado sentir dentro de los Parques Nacionales, así como en otros espacios y que tal proceso ha acarreado cambios importantes en el paisaje.

La función de los acuerdos administrativos. Entre los principales instrumentos que las autoridades de los Parques Nacionales y otros organismos como la Countryside Commission y el Nature Conservancy Council utilizan para lograr sus objetivos de conservación, hay que mencionar algunas formas de acuerdos con los propietarios. Un ejemplo concreto de dichos acuerdos tiene que ver con el acceso: se trata de intentar facilitar al gran público el acceso a paisajes atractivos situados en zonas de propiedad privada. Otro ejemplo lo constituyen acuerdos más específicos sobre el uso de la tierra y la administración de la misma. Acuerdos de este tipo incluyen un «... documento formal firmado por una autoridad pública y un propietario ... que así se compromete a administrar la tierra de una forma específica ...» (Curtis, 1991: 464). Normalmente, en todos estos casos, se efectúa un pago de indemnización ó compensación.

La experiencia de estos acuerdos administrativos no es del todo positiva. En muchas ocasiones se han roto las negociaciones sobre el valor preciso y apropiado de la indemnización a pagar al agricultor y han surgido severas dificultades para hacer cumplir un acuerdo cuando éste se ha violado (Feist, 1979). En la práctica, es probable que la autoridad de un Parque Nacional no disponga de los recursos de tiempo y de dinero para perseguir al individuo que ha roto el acuer- 
do. Surgen considerables dificultades relacionadas con el período de vigencia del acuerdo y con la vinculación o no de éste con la tierra si, por ejemplo, ésta se transfiere a otro propietario. Con razón, los propietarios han sospechado que tales acuerdos pueden reducir el valor potencial de sus tierras en el mercado (Blacksell and Gilg, 1981).

Los acuerdos de acceso han tenido más éxito, debido principalmente a que los propietarios pueden ver el beneficio potencial para ellos de restringir el acceso público a rutas y sendas concretas, pero aún así se plantean problemas parecidos a los que se producen en el caso de los acuerdos administrativos.

A pesar de lo anterior, el criterio oficial del gobierno es que «... se puede lograr un mayor acceso al campo abierto dentro de los Parques Nacionales colaborando con los que viven de la tierra. Hay mucho más potencial del que hasta ahora se percibe para el uso de las medidas existentes, mediante acuerdos administrativos o mediante acuerdos de acceso ... El gobierno considera que tales acuerdos constituyen la mejor solución al problema» (Department of the Environment, 1992: 7). El trasfondo de esta declaración era la evidencia creciente de que en algunas áreas el acceso se hacía cada vez más restringido (Edwards, 1991).

Similares a los acuerdos administrativos que las autoridades de los Parques Nacionales pudieron negociar con los terratenientes locales, son los acuerdos que el Nature Conservancy Council (English Nature) intentaba firmar con los propietarios de SSSIs para tratar de asegurar que éstos fueran administrados de forma que conservaran su flora y su fauna o sus características geológicas. Sin embargo, los recursos financieros disponibles para lograr este objetivo nunca han sido suficientes y muchos propietarios opinaban que obtendrían más provecho mejorando sus cultivos (Green, 1981). Por ejemplo, las subvenciones concedidas por el Ministerio de Agricultura para modernizar las explotaciones (relacionadas en su mayor parte a la promoción de la intensificación agrícola) fueron de 540 millones de libras esterlinas en 1978; sin embargo, el presupuesto total del Nature Conservancy Council era sólo de $£ 7$ millones (Evans, 1992). En 1985 se calculaba que hacían falta entre 20 y 30 millones de libras esterlinas para financiar auténticos acuerdos administrativos para los cinco mil SSSIs que existían en aquel momento (Adams, 1986). Sigue existiendo el problema de que los recursos son insuficientes para financiar

$$
-179-
$$


debidamente los acuerdos administrativos en esos sitios. Se ha calculado que cada año se dañan 100 sitios, algunos de ellos de forma irreversible (Evans, 1992). Muchas autoridades opinan ahora que tendría más sentido aprovechar los fondos disponibles para llevar a cabo un programa completo de compra de los SSSIs que facilitar subvenciones para poner fin a su destrucción potencial.

\section{Conclusión}

Cualquier conclusión acerca de la experiencia del sistema británico para la protección de los paisajes tiende a ser más pesimista que optimista. Tal vez la principal razón de ello es el fracaso en afrontar la contradicción fundamental que aparece constantemente en el seno de las medidas de protección del paisaje británico -el paisaje británico, ¿es un derecho de propiedad individual o un bien público colectivo?-. En este contexto, puede ser útil el concepto de sustentabilidad¿qué es lo que la política pretende «sustentar»?, ¿un espacio para esparcimiento y diversión donde los hábitats estén exentos de amenazas, o un paisaje que evolucione en respuesta a las demandas inexorables de una economía rural cada vez más dominada por el capitalismo internacional orientado al comercio de productos agrícolas?

Incluso dentro de las áreas de los Parques Nacionales se han producido serios enfrentamientos relacionados con desarrollos a gran escala que han ignorado la ética de la conservación. Sin embargo, es probable que en realidad las tendencias con menos interés periodístico hayan sido las más perniciosas y fundamentales. Durante la mayor parte del período de posguerra, se suponía que las prácticas agrícolas por así mismas armonizaban con los objetivos de la conservación, pero en años recientes el desarrollo de métodos agrícolas intensivos ha planteado una de las principales amenazas al paisaje rural. Al mismo tiempo, el desarrollo de nuevas formas de actividades de ocio al aire libre, más dinámicas y más ajenas ha originado nuevas fuentes de conflicto. Además, se han producido cambios fundamentales en la estructura de las comunidades rurales, que han alterado el equilibrio entre los que viven y trabajan en el campo y los que sólo viven allí de forma temporal.

$$
-180-
$$


A pesar de todo lo anterior, surgen novedades que infunden cierto optimismo, siendo quizás la más importante la creciente fuerza y compromiso del movimiento conservacionista en Gran Bretaña (Evans, 1992). Si persiste este fenómeno, el gobierno u otros organismo implicados encontrarán dificultad para comportarse de una forma insustentable. Es realmente asombroso el número de organizaciones directamente involucradas, de alguna u otra forma, en la conservación. El reto principal para el próximo siglo será la definición coordinada de una serie de prioridades entre estos grupos para que su impacto en la política de la conservación sea más decisivo.

\section{BIBLIOGRAFIA}

Adams, W. M. (1986): Nature's Place: Conservation Sites and Countryside Change, Allen \& Unwin, London.

Best, R. H. and Champion, A. G. (1970): Regional conversions of agricultural land to urban use in England and Wales, Transactions, Institute of British Geographers, 49, pp. 15-31.

Blacksell, M. and Gilg, A. (1981): The Countryside: Planning and Change, Allen and Unwin, London.

Blunden, J. and Curry, N. (1988): A Future for Our Countryside, Blackwell, Oxford.

Bush, R. (1973): The National Parks of England and Wales, J. M. Dent, London.

Cherry, G. E. (1975): National Parks and Recreation in the Countryside: Environmental Planning, vol. II, HMSO, London.

Clark, G. (1982): «Housing policy in the Lake District», Transactions, Institute of British Geographers, N.S., 7 (1), pp. 59-70.

Countryside Commission (1977): The Broads: Possible Courses of Action. Countryside Commission, London.

Countryside Commission (1991): Landscape Change in the National Parks. Countryside Commission, Cheltenham.

Countryside Commission (1993): Annual Report 1992-93. Countryside Commission. Cheltenham.

Cox, G. and Lowe, P. (1983): «A battle not the war: the politics of the Wildlife and Countryside Act», Countryside Planning Yearbook, Geo Books, Norwich.

CRIPPS, J. (1980): The Countryside Commission: its first decade Countryside Planning Yearbook. 1, pp. 38-48.

Curry, N. (1989): Development Pressure in National Parks, 1983-1988, Countryside Commission, Cheltenham.

CuRTIS, L. F. (1991): «Conservation and protection», pp. 449-472, in Johnston, R. J. and GARDINER, V. (eds.): The Changing Geography of the United Kingdom, Routledge, London, Second Edition.

Department of THE Environment (1992): Fit for the Future: A Statement by the (Government on Policies for the National Parks, Department of the Environment, London.

Dower, M. (1965): Fourth Wave: the Challenge of Leisure, Civic Trust, London.

EDwards, R. (1991): Fit for the Future: Report of the National Parks Review Panel Countryside Commission, Cheltenham. 
Evans, D. (1992): A History of Nature Conservation in Britain Routledge, London.

FEDDEN, R. (1974): The National Trust Cape, London.

Feist, M. J. (1979): A Study of Management Agreements Countryside Commission, Cheltenham.

GreEN, B. (1981): Countryside Conservation Allen and Unwin, London.

Groome, D. (1993): Planning and Rural Recreation in Britain Avebury, Aldershot.

Lowe, P. and Goyder, J. (1983): Environmental Groups in Politics Allen \& Unwin, London.

Malpass, P. (1980): «Council house sales in Yeovil District», Policy and Politics, 8, pp. 308-15.

McEwan, A. and McEwan, M. (1982): National Parks: Conservation or Cosmetics?, Allen and Unwin, London.

National Park Authority, The (1993): Purposes Powers and Administration Countryside Commission. Cheltenham.

Newby, H. (1979): Green and Pleasant Land?, Pelican, Harmondsworth.

- (1988): The Countryside in Question, Hutchinson, London.

Open University (1985): The Countryside Handbook, Croom Helm. London.

Owens, P. L. (1990): "Leisure and the Countryside», pp. 100-132, in Bayliss-Smith, T. and Owens, S. (eds.): Britain's Changing Environment from the Air, Cambridge University Press, Cambridge.

Phillips, A. (1993): «The National Parks - will they be fit for the future?», Ecos, 14 (3/ 4), pp. 30-36.

Poore, D. and Poore, J. (1987): Protected landscapes: The United Kingdom Experience. Countryside Commission, Manchester.

RaIKES, G. (1990): «Clocking up the miles», The National Trust Magazine, No. 59, Spring, p. 19.

Seabrooke, W. and Miles, C. W. N. (1993): Recreational Land Management 2nd ed., E. and F. N. Spon, London.

ShoARD, M. (1987): This Land is Our Land, Paladin Grafton, London.

SPINK, J. (1994): Leisure and the Environment, Butterworth Heinemann, London.

TunBRIDGE, J. E. (1981): "Conservation trusts as geographic agents: their impact upon landscape, townscape and land use», Transactions, Institute of British Geographers, N. S., 6 (1), pp. 103-135. 